\title{
Proposta de Software na Disciplina Computação Aplicada à Medicina
}

\author{
Catiane Schaefer, Bruna Ebert, Letícia Grespan, \\ Juliana da Rosa Wendt, Marcia Elena Jochims Kniphoff da Cruz
}

\author{
Departamento de Ciências da Saúde, Universidade de Santa Cruz do Sul (UNISC) \\ Santa Cruz do Sul - RS - Brasil \\ catianeschaefer@mx2.unisc.br, brunaebert@mx2.unisc.br, grespan@mx2.unisc.br, \\ julianawendt@unisc.br,mcruz@unisc.br
}

\begin{abstract}
This work presents a report referring to a proposal for the software 'Infomed', designed by medical students, in the discipline of Computing Applied to Medicine. Preparing the future physician to participate in multidisciplinary software development teams is essential. The results demonstrate that innovative software ideas can be generated in the discipline and encourage the approach to Computing themes in the Medicine course.

Resumo. Este trabalho apresenta um relato referente a uma proposta do software denominado 'Infomed', projetada por estudantes do curso de Medicina, na disciplina 'Computação Aplicada à Medicina'. A preparação do futuro médico para a participação em equipes multidisciplinares de desenvolvimento de software é imprescindível. Os resultados demonstram que ideias de software inovador podem ser geradas na disciplina e incentivam a abordagem de temáticas da Computação no curso de Medicina.
\end{abstract}

\section{Introdução}

A formação acadêmica do estudante de Medicina vem sendo atualizada e para isso é necessário avançar nos estudos sobre a Computação, como base para desenvolvimento das tecnologias utilizadas na área da saúde. As Diretrizes Curriculares Nacionais para a Graduação em Medicina (BRASIL, 2014) indicam que o graduado em Medicina deve possuir habilidades no uso de dispositivos de todas as densidades tecnológicas, de forma a auxiliar na organização de sistemas integrados, além de promover criatividade e inovação, incorporando, sempre que possível, novas tecnologias de informação e comunicação. As Diretrizes recomendam, ainda, que sejam oferecidas aos acadêmicos de Medicina, durante a graduação, estímulos à escolha de estratégias interativas para a construção e a socialização de conhecimentos, bem como a compreensão e o domínio das novas tecnologias, e o favorecimento ao desenvolvimento científico e tecnológico voltado para a atenção das necessidades de saúde individuais e coletivas (BRASIL, 2014). Na Universidade de Santa Cruz do Sul (UNISC), essas habilidades são trabalhadas na disciplina Computação Aplicada à Medicina, pertencente ao módulo 'Saúde, Sociedade e Fundamentos em Pesquisa IV'.

A disciplina aborda a exploração de software existente para área da saúde, repositórios de dados digitais como DataSus, introdução aos conceitos de Inteligência Artificial e Ciência dos Dados, entre outras temáticas, e incentiva a criatividade dos estudantes no desenvolvimento de ideias inovadoras. Tais ideias, em conformidade com as Diretrizes Curriculares Nacionais 
(BRASIL, 2014), são articuladas por meio de projetos que propõem mockup de aplicativos que possam ser úteis à área da Saúde, considerando que, já na graduação, esses estudantes possam integrar equipes multidisciplinares de desenvolvimento de software como incentivo ao empreendedorismo na área da saúde e atuação junto ao projeto de extensão UNISC Inclusão Digital. A metodologia adotada para o projeto foi Design Thinking, sendo que, ao final da disciplina, os estudantes desenvolveram mockup para representar as propostas de software.

Foram desenvolvidos na disciplina quatorze projetos e neste trabalho o projeto 'Infomed' é apresentado como resultado. O 'Infomed' é a proposta de aplicativo para explicitar, de maneira simples e didática, a fisiopatologia das doenças, como elas agem no organismo e, principalmente, qual o propósito dos tratamentos mais preconizados.

\section{Fundamentação Teórica}

Muito se discute sobre a utilização da tecnologia a favor da saúde, destinada a auxiliar o profissional especialista em saúde ou para conforto e atenção ao paciente. Este trabalho ressalta a necessidade de software voltado à informação sobre doenças confiável ao cidadão como forma de educação e promoção da saúde, questão trabalhada em menor escala, quando relacionada à oferta de aplicativos para telefones móveis.

É necessário considerar que a Internet é cada vez mais consultada pela população para buscas de informações sobre saúde. Durante a pandemia causada pelo vírus SARS-CoV-2, conforme segunda edição do Painel TIC COVID-19 mostrou que 72\% dos usuários de Internet procuraram informações ou usaram serviços públicos on-line relacionados aos direitos do trabalhador ou previdência social, tais como INSS, FGTS, seguro-desemprego, auxílio emergencial ou aposentadoria; percentual que era de $40 \%$ da população de referência em 2019. Na sequência, os serviços mais buscados ou realizados on-line foram os relacionados a documentos pessoais com percentual de 46\%, saúde pública com 45\% de acessos e educação pública com 37\% (CETIC, 2020).

A oferta de ferramentas digitais como aplicativos para telefones móveis cresce exponencialmente, contudo, ao consultar a Google Play Store com os termos "informações sobre doenças", a maioria dos resultados apontam dicionários e atlas. Um aplicativo denominado "SOS Tratamentos' é correlato ao aplicativo proposto neste trabalho, oferecendo informações sobre doenças, porém, por ser desenvolvido por empresa privada, é necessária a aquisição por meio financeiro para utilização (Androidista, 2021). Páginas e portais que apresentam informações sobre doenças também estão disponíveis na Internet, a exemplo da 'MD Saúde' que é voltada para a população em geral, com textos escritos em linguagem acessível e pouco técnica, apresentando informações baseadas em guidelines internacionais e literatura médica revisada por pares.

Com a intenção de contribuir para a promoção de informações sobre doenças com elevado grau de embasamento científico e correção à população, contribuindo na perspectiva da educação em saúde, o aplicativo 'Infomed' foi planejado.

\section{Método}

A metodologia utilizada na disciplina 'Computação Aplicada à Medicina' é orientada pela proposta 'Flipped Classroom' ou 'Sala de Aula Invertida' (GOMES, 2012). Os estudantes foram convidados a conhecer o conteúdo antes de cada aula, para, durante o período de aula, discutir sobre a temática 
em pauta. $\mathrm{O}$ trabalho em equipe foi incentivado e proposto aos estudantes de Medicina por meio de 'Design Thinking' para o processo de criação das ideias de aplicativos para a área da saúde. O 'Design Thinking', segundo Arruda (2020), é uma metodologia de desenvolvimento de produtos e serviços focados nas necessidades, desejos e limitações dos usuários, envolvendo as fases: Imersão, Análise e Síntese, Ideação, Prototipagem e Teste. As equipes foram incentivadas a realizar reuniões de trabalho e, ao final do processo, apresentar mockup das ideias desenvolvidas, sendo que uma das equipes apresentou o 'Infomed'. Os mockup são desenhos ou esboços de telas que servem para mostrar de maneira direta a arquitetura e o fluxo de navegação de como o aplicativo final ficará (MENDES et al., 2020).

\section{Resultados}

Considerando que a Internet tem sido extremamente acessada para pesquisa de doenças pela população em geral, sendo fonte de informações úteis e corretas, mas também, muitas vezes, de notícias falsas, o aplicativo 'Infomed' foi proposto. Nele, as informações serão reproduzidas de maneira didática, através de imagens, vídeos, gráficos, tabelas e textos, baseados em evidências científicas, para que o público leigo consiga compreender e não seja cativado por informações falsas que a Internet pode conter. Por meio do aplicativo, o usuário ou paciente digita o nome da doença na barra de buscas e, após uma rápida procura, o aplicativo exibe dados como características sobre a enfermidade, exames que podem ser realizados, sintomas e quais as opções de tratamento que podem ser indicadas pelo profissional médico. Dessa forma, o aplicativo permitirá que os usuários ou pacientes compreendam da melhor forma os aspectos de uma determinada doença, o que, de acordo com Miller (2016), traz benefícios como o aumento nas taxas de adesão destes aos tratamentos que lhes são indicados pelos médicos.

A Figura 1 apresenta as principais telas propostas para o 'Infomed'. A primeira tela é a de recepção do usuário, na segunda tela é apresentada a barra de pesquisa e na terceira o resultado para a busca realizada.
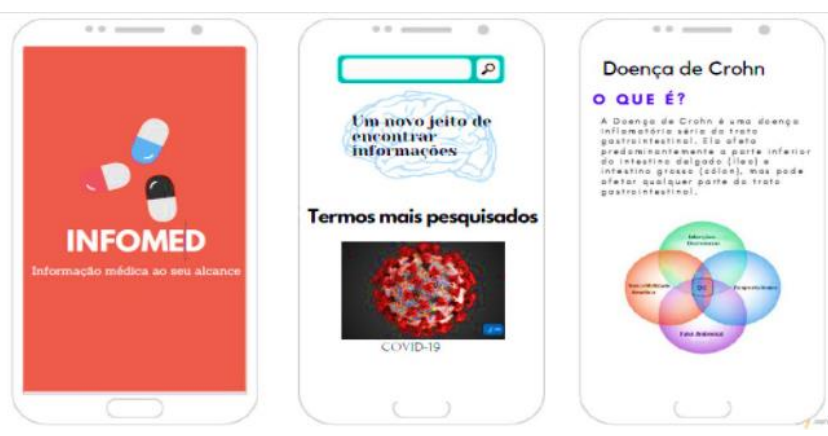

Figura 1: Propostas de tela para o aplicativo 'Infomed'

Em levantamento realizado com os estudantes ao final da disciplina, observou-se que as equipes apresentaram ideias inovadoras de software úteis à área e consideram-se mais aptos a participar de equipe de desenvolvimento de software como especialistas humanos da área da saúde.

\section{Considerações Finais}

As áreas da Computação e Saúde estreitam os laços e avançam na oferta de soluções que impactam positivamente no trabalho do Médico, no desenvolvimento de software e na saúde da população. 
Este trabalho apresentou o método de trabalho adotado na disciplina 'Computação Aplicada à Medicina' que busca intensificar a proximidade entre as áreas citadas e encaminha atividades que demonstram ao futuro médico caminhos para participar de equipe interdisciplinar de desenvolvimento de software. O desenvolvimento de aplicativos voltados para a área da saúde oportuniza o aperfeiçoamento de habilidades que serão utilizadas também na rotina dos hospitais e consultórios, em consonância com a proposta de incentivar o desenvolvimento tecnológico voltado para a atenção das necessidades de saúde das Diretrizes Curriculares Nacionais para a Graduação em Medicina (BRASIL, 2014).

Ao estudante de Medicina a experiência oportunizou a ideação de um aplicativo que visa ser de fácil entendimento para o usuário ou paciente, aprimorando a compreensão de qual a melhor maneira de se repassar as informações baseadas em evidências científicas sobre doenças, levando os avanços da Medicina para toda a população, através de meios computacionais que são efetivos e que alcançam uma parcela significativa de pessoas.

\section{Referências}

ANDROIDISTA. SOS Tratamentos. Disponível em: https://www.androidlista.com.br/item/androidapps/695854/sos-tratamentos/. Acesso em 10 de jun. 2021.

ARRUDA, Mariana. O que significa Design Thinking? Agência USP de Inovação (AUSPIN). Disponível em: http://www.inovacao.usp.br/o-que-significa-design-thinking/. Acesso em 08 de jun. 2021.

BRASIL. Ministério da Educação. Resolução no 3, de 20 de junho de 2014. Institui Diretrizes Curriculares Nacionais do Curso de Graduação em Medicina e dá outras providências. Brasília: Ministério da Educação, 2014. Disponível em:

http://portal.mec.gov.br/index.php?option=com_docman\&view=download\&alias=15874-rces00314\&category_slug=junho-2014-pdf\&Itemid=30192. Acesso em: 11 jun. 2021.

BRASIL. Ministério da Saúde - DataSus. Portal da Saúde. Disponível em: http://www2.datasus.gov.br/DATASUS/index.php. Acesso em 08 de jun. 2021.

CETIC. Painel TIC COVID-19 apresenta dados inéditos sobre acesso a serviços públicos on-line e desafios à privacidade durante a pandemia. Centro Regional de Estudos para o Desenvolvimento da Sociedade da Informação, 2020. Disponível em: Acesso em 28 de jun. 2021.

GOMES, Patrícia. Sala de aula invertida chega a médicos de Stanford. Porvir inovações em educação. Disponível em: https://porvir.org/sala-de-aula-invertida-chega-medicos-de-stanford/. Acesso em 06 jun. 2021.

GOOGLE PLAY. Google Play Store. Disponível em: https://play.google.com/store/. Acesso em 08 de jun. 2021.

MD Saúde. MD.Saúde. Disponível em: https://www.mdsaude.com/. Acesso em 10 de jun. 2021.

MENDES, Cristiane B. et al. Aplicativo móvel educativo e de follow up para pacientes com doença arterial periférica. Revista Latino-Am. Enfermagem, 2019. Disponível em:

https://www.scielo.br/j/rlae/a/DKgxTqYXXRJDHfmqF5yGC9j/?lang=pt\&format=pdf. Acesso em 10 de jun. 2021.

MILLER, Tricia A. Health literacy and adherence to medical treatment in chronic and acute illness: A meta-analysis. Patient education and counseling, v. 99, n. 7, p. 1079-1086, 2016. 